http://jmscr.igmpublication.org/home/

ISSN (e)-2347-176x ISSN (p) 2455-0450

crossref DOI: https://dx.doi.org/10.18535/jmscr/v7i11.149

Journal Of Medical Science And Clinical Research

IGM Publication

An Official Publication of IGM Publication

\title{
Clinico-pathological Profile of Pancreatic Cancer at National Cancer Institute - Misurata Libya from Feb 2016 to Dec 2018
}

\author{
Authors \\ Mussa Elrgig', ${ }^{1}$ aji Zubia ${ }^{2}$, Ramadan Elamyal ${ }^{3 *}$, Mohammed Elfaqieh ${ }^{4}$, \\ Abdallah Juwid ${ }^{5}$, Feras Seaeb ${ }^{6}$ \\ 1,3,4,5 MD Consultant Surgeon, NCI Misurata Libya \\ ${ }^{2}$ MD Specialist Surgeon, NCI Misurata Libya \\ ${ }^{6}$ Registrar, Surgery department, NCI Misurata Libya \\ *Corresponding Author \\ Ramadan Elamyal \\ Department of Surgery, National Cancer Institute (NCI), Misurata Libya
}

\begin{abstract}
Introduction: The pancreas is a glandular organ of dual composition with both exocrine and endocrine components. Tumors of exocrine pancreas are rare with more than 95\% being malignant.

Methods \& Materials: This is a retrospective clinico-histopathological study of 61 cases registered in our institute from Feb 2016 to Dec 2018. The details of patients were retrieved from patients' files. Information retrieved included socio-demographic data, clinical presentation, anatomical site, gross appearance, tumor stage, histopathological type and grade, presence of metastasis.

Results: During the study period, a total of 61 malignancies were registered. Of these, 23 (37\%) were histopathologically confirmed pancreatic cancer. The diagnosis in the remaining 38 patients was based on clinical and radiological basis. Male to female ratio of 1.4:1. The age ranged from 40 to 90 years with a median age of 64 years. Forty nine patients (80\%) presented with abdominal pain,13 patients (21\%) were jaundiced. Thehead was the most frequent site for pancreatic tumor in 48 (54\%) cases followed by tail, body. Adenocarcinoma was the most common histopathological tumor in 43(90\%) patients. Thirty(33.7\%) patients were presented in locally advanced stages and 54(60.6\%) patients had metastasis.

Conclusion: The study was limited by being a retrospective, a relatively small number of patients and representing the experience of a single cancer institute, therefore, larger prospective studies are recommended to study the clinicodemografic character of this disease in the country.

Keywords: Pancreatic Cancer, clinical, demographic, retrospective.
\end{abstract}

\section{Introduction}

The pancreas is a glandular organ of dual composition with both exocrine and endocrine components ${ }^{[1,2]}$. Tumors of exocrine pancreas are rare with more than $95 \%$ being malignant ${ }^{[3]}$. Several risk factors for pancreatic cancer have been identified, such as smoking ${ }^{[4]}$, age ${ }^{[5]}$, family history $^{[6]}$, and diabetes ${ }^{[7]}$. The majority of pancreatic cancers are of exocrine origin and majority of adenocarcinomas type, commonly involving the head and body of the pancreas ${ }^{[8]}$. Cancer of pancreas is most commonly seen in the 7 th and 8th decades with a median age of 71 years at diagnosis. Early pancreatic cancer has no 
specific symptoms and signs and there is no established screening strategy to detect it early. However, at the time of diagnosis, $24 \%$ of patients have locally advanced disease and 54\% have distant metastases ${ }^{[9]}$. The purpose of the study is to study exocrine pancreatic cancers clinicopathologically to know the various types, grades and clinical manifestations.

\section{Methods and Materials}

This is a retrospective clinico-histopathological study of 61 cases registered in our Center from feb 2016 to Dec 2018. The details of patients were retrieved from patients' files. Information retrieved included socio-demographic data, clinical presentation, anatomical site, gross appearance, tumor stage, histopathological type and grade, presence of metastasis.

\section{Results}

During the study period, a total of 61 malignancies were registered. Of these, 23 $(37.70 \%)$ were histopathologically confirmed pancreatic cancer. The diagnosis in the remaining 38 patients was based on clinical and radiological basis. The number of males was35 $(57.37 \%)$ and the number of females was $26(42.63 \%)$ with a male to female ratio of $1.3: 1$. The age ranged from 40 to 90 years with a median age of 64 years. Table 1.

Table 1 Demographic data of 62 patients with pancreatic cancer

\begin{tabular}{lr}
\hline Gender & \\
Male & $35(57.37 \%)$ \\
Female & $26(42.63 \%)$ \\
\multicolumn{2}{l}{ Mean age (SD), range61( } \\
40-90)
\end{tabular}

Fifty seven patients (64\%) presented with abdominal pain, 41 patients $(46 \%)$ were jaundiced, 29 patients (32\%). Thirty seven patients $(42 \%)$ had history of diabetes and 41 patients $(46 \%)$ are smokers. Table (2).
Table 2 Distribution of patients according to clinical presentation

\begin{tabular}{|l|c|}
\hline Symptoms \&Signs & No (\%) \\
\hline & \\
Abdominal pain & $49(80 \%)$ \\
Obstructive Jaundice & $13(21 \%)$ \\
Loss of weight & $29(32 \%)$ \\
Anorexia & $23(26 \%)$ \\
Nausea\&Vomiting & $21(23 \%)$ \\
Malaise & $07(7 \%)$ \\
Dyspnea\&Cough & $05(5 \%)$ \\
Fever & $02(2 \%)$ \\
Subcutaneous nodules & $01(1 \%)$ \\
PMH Diabetes & $37(42 \%)$ \\
History of smoking & $\mathbf{4 1}(46 \%)$ \\
\hline
\end{tabular}

The head was themost frequent site for pancreatic tumor in $48(54 \%)$ cases followed by tail, body and diffuse in $10(11 \%), 8(9 \%)$ and $23(25 \%)$ cases, respect. Table 3 .

Table 3 show site distribution of pancreatic cancer

\begin{tabular}{|l|c|}
\hline Site of tumors & No (\%) \\
\hline Head & $48(54 \%)$ \\
Tail & $10(11 \%)$ \\
Body & $8(9 \%)$ \\
More than one subsite(Diffuse) & $23(25 \%)$ \\
\hline
\end{tabular}

Microscopically, adenocarcinoma was the most common histopathological type in 43(90\%) patients. Carcinoid, Mucinous cystadenocarcinoma and acinar cell carcinomas accounted for $2(4 \%), 1(2 \%)$ and $1(2 \%)$ patients, respectively. Only one patient $(2 \%)$ wasmixed adenocarcinoma and carcinoid. Table 4.

Table 4 Show Histopathology Types

\begin{tabular}{|l|c|}
\hline \multicolumn{1}{|c|}{ Histopathology* } & No (\%) \\
\hline Adenocarcinoma & $\mathbf{4 3}(\mathbf{9 0 \% )})$ \\
Carcinoid & $\mathbf{2 ( 4 \% )}$ \\
Mucinous cyst adenocarcinoma & $1(2 \%)$ \\
Acinar cell carcinoma & $1(2 \%)$ \\
Mixed adenocarcinoma \&carcinoid & $1(2 \%)$ \\
\hline
\end{tabular}

*Histopathology was confirmed in $23(37.70 \%)$ patients.

During the study period, a total of 61 malignancies were registered. Of these, 23 $(37.70 \%)$ were histopathologically confirmed pancreatic cancer. The diagnosis in the remaining 38 patients was based on clinical and radiological basis 
Regarding extent of disease, only 5 (5.6\%) patients were identified as being in early stages, $30(33.7 \%)$ patients were presented in locally advanced stages and 54(60.6\%) patients had metastasis. Table 5.

Table 5 show extent of the disease.

\begin{tabular}{|l|c|}
\hline Extent of disease & No (\%) \\
\hline Early stage & $5(5.6 \%)$ \\
Locally advanced & $30(33.7 \%)$ \\
Metastasis & $54(60.7 \%)$ \\
\hline
\end{tabular}

\section{Discussion}

Advancing age and male gender are the two main demographic risk factors for pancreatic cancer ${ }^{[10]}$. In the present study, the median age was 63 years and majority of cases of adenocarcinomas were found in the fifth and sixth decade (57\%). Compared to the median age of 72 years in United State $^{[11]}$, our patients present at approximately 8 years younger median age. This may be attributed to overall younger population pool in Libya or may be due to different biology of the cancer. Dohert et $\mathrm{al}^{[12]}$ showed that seventy five $(75 \%)$ of pancreatic cancer patients presented with weight loss, obstructive jaundice and upper abdominal pain. Upper abdominal pain (53\%) and weight loss $(40 \%)$ were also common first symptoms ${ }^{[13]}$. In our study, sixty-four percent $(80 \%)$ of pancreatic cancer patient presented with abdominal pain, $21 \%$ with obstructive jaundice and $39 \%$ with loss of weight. Other modes of presentations in our study were anorexia (15 patients 24\%), nausea \&vomiting (11 patients 17\%), Dyspnea \& cough (3 patients 5\%) and fever (3 patients 5\%). No patients in our study were presented with bone pain. Diabetes mellitus and cigarette smoking may be possible risk factors for development of carcinoma of exocrine pancreas ${ }^{[14]}$. In this study, 25cases $(41 \%)$ had diabetes mellitus and 7 cases $(11 \%)$ were smokers. The majority of pancreatic cancers are adenocarcinomas. These tumours originate in the epithelial cells lining the pancreatic duct, form gland-like structures, and account for $90 \%$ of all pancreatic cancers ${ }^{[1,15,16]}$. In the present study, adenocarcinoma constituted the majority $(90 \%$ patients) and is comparable to the study by Kumar $\mathrm{NV}^{[17]}$ in which $(89.7 \%)$ of cases were adenocarcinomas. Almost one third of our patients present at advanced stage and sixty percent present withdistant metastasis compared to $53 \%$ in United Stateof America ${ }^{[18]}$. This was may be due to the scarcity of specialized centers and investigations facilitiesin our country so, a considerable number of patients remain undiagnosed or diagnosed at the advanced stage of the disease.

\section{Conclusion}

Our study was limited by its smaller number of patients, being retrospectivein natureand representing the experience of a single cancer Institute, therefore,larger studies are required to study the clinical and demographic character of this disease in our country.

\section{References}

1. Rosai J. Pancreas and ampullary region. In: Rosai and Ackerman's Surgical Pathology. 10th ed. Missouri: Elsevier Mosby: 2011.

2. Hollingsworth MA. Proteins expressed by pancreatic duct cells and their relatives. Ann N Y Acad Sci1999; 880:38-49.

3. Hruban RH, Donahue DL. The Pancreas. In: Kumar, Abbas, Fasuto, Aster, editors. Robbins and Cotran Pathologic Basis of Disease. 8th ed. Philadelphia: Elsevier Saunders; 2010. p. 891-903.

4. Warshaw AL, Castillo CF. Pancreatic carcinoma. N Engl J Med1992; 326:45565.

5. Ghadirian P, Lynch HT, Krewski D. Epidemiology of pancreatic cancer: an overview. Cancer Detect Prev2003; 27: 87-93.

6. Lynch HT, Smyrk T, Kern SE, et al. Familial pancreatic cancer: a review. SeminOncol1996; 23:251-75. 
7. Everhart J, Wright D. Diabetes mellitus as a risk factor for pancreatic cancer: a metaanalysis. JAMA 1995; 273:1605-9.

8. Dhir V, Mohandas K. Epidemiology of digestive tract cancers in India IV. Gall bladder and pancreas. Indian $J$ Gastroenterol1999; 18(1): 24-8.

9. Cancer Facts \& Figures. American Cancer Society. Available at http://www.cancer.org/Research/CancerFa ctsFigures/index. Accessed: October 8, 2014.

10. Gold E.B., and Goldin B. Epidemiology of and risk factors for pancreatic cancer. SurgOncolClin North Am 1998; 7:67-91.

11. Howlader N, Noone AM, Krapcho M, Neyman N, AminouR, Waldron W, et al, editors. SEER Cancer Statistics Review1975-2008 National Cancer Institute SEER Cancer StatisticsReview 1975-2008 National Cancer Institute. Bethesda (MD):National Cancer Institute; 2011.

12. Doherty GM, Way LW. Pancreas. In: Way LW, Doherty GM, editors. Current surgical diagnosis and treatment. New York:Lange Medical Books; 2003. pp. 602-12.

13. Sonnefeld T, Nyberg B, Perbeck L. The effect of palliative biliodigestive operations for unresectable pancreatic carcinoma.J ActaChirScand Suppl. 1986; 530:47-50.

14. Shi C, Hruban RH, Klein AP. Familial pancreatic cancer. Arch Pathol Lab Med 2009; 133: 365-74.

15. Cowgill SM, Muscarella P. The genetics of pancreatic cancer. Am J Surg 2003; 186: 279-86.

16. Li D, Jiao L. Molecular epidemiology of pancreatic cancer. Int $\mathbf{J}$ Gastrointest Cancer 2003; 33:3-14.
17. Kumar NV. Clinical study of carcinoma pancreas [dissertation]. Mangalore: Rajiv Gandhi Univ.; 2007.

18. American Cancer Society. Cancer Facts \& Figures 2011. USA:American Cancer Society, Inc.: 2011. p. 1-55. 